\title{
Separating Gratitude from Guilt in the Laboratory*
}

\author{
Hong (Hannah) Lin $^{1}$ and David Ong ${ }^{2}$
}

\begin{abstract}
In contrast to guilt based reciprocity, which hypothesizes that reciprocity is an increasing function of the $2^{\text {nd }}$ order expectation of trustor's expectation for reciprocation, we test for reciprocity which is a decreasing function of trustees $2^{\text {nd }}$ order expectations, i.e., that people can reciprocate out of gratitude. To unambiguously decrease $2^{\text {nd }}$ order expectations in our treatment, we broke up a standard trust game into a two stage dictator game where the $1^{\text {st }}$ round dictator was not informed about the possibility of a $2^{\text {nd }}$ round. Furthermore, the $2^{\text {nd }}$ dictator could "silently exit" by not sending anything to the $1^{\text {st }}$ round dictator. We found a significant increase in both the amount of reciprocation and the number of people reciprocating as compared to our standard trust and dictator games controls. The strength of the positive reciprocity observed rules out inequality aversion as a cause. We found support for our hypothesis in the prior data of others who tested for guilt based reciprocity. Our result also seems to reconcile conflicting results in that literature. To our knowledge, this is the first paper which shows that kindness distinct from guilt, shame, efficiency and inequity aversion could be a motive for reciprocity. Our strong positive reciprocity result also suggests why it has been difficult to find in the past.
\end{abstract}

JEL Codes: C91, C72, D64

Keywords: reciprocity, guilt, gratitude, trust game, double-blind, silent exiting

\footnotetext{
${ }^{1}$ Email: hlin05@gmail.com, Tel: +86-136-3263-7246, Fax: +86-755-2603-5344, Address: N1007, PKU, Univ.Town, Shenzhen, P.R.C, 518055.

${ }^{2}$ Corresponding author email: dvdong@gmail.com, Tel: +86-755-2603-2655, Fax: +86-755-2603-5344, Address: C402, PKU, Univ.Town, Shenzhen, P.R.C, 518055.

* This research was funded by the Dean's Fund No.2009039, Peking University Shenzhen Graduate School. The author gratefully acknowledge the helpful comments of Luz Marina Arias, Zhuoqiong (Charlie) Chen, Zemin (Zachary) Zhong, Tore Ellingsen, Ernesto Reuben, Wooyong Lim, Alexander Smith, the participants in our session at the Economic Science Association North American Meeting, Chicago, July 2011.
} 


\section{INTRODUCTION}

The importance of reciprocity has long been recognized in economics, particularly in contracting when institutions of legal enforcement are underdeveloped or absent, e.g., in emerging markets, or in social settings where contracts are implicit and informal. Prior experimental literature has largely demonstrated that people are not entirely selfish (in the colloquial sense of the word). However, as Charness and Rabin (2002) pointed out, evidence for positive reciprocity, where recipients of favor respond more generously than dictators with the same amount of endowment, has been elusive. They regarded McCabe et al., (2003) as a notable exception in the literature. However, even in that experiment, inequity aversion and psychological motives like guilt and shame, which are not obviously forms of positive reciprocity, are still possible confounds. These psychological confounds could also explain why positive reciprocity has been difficult to find in other experiments where beliefs had generally not been the focus of the experiment and hence, were not well controlled. In standard gift exchange or trust experiments, recipients could believe that the sender gave in order to incite reciprocation. In that case, the recipients might have doubts about the senders' generous motives and hence, might feel that positive reciprocity was not warranted. Thus, we believe that a test of positive reciprocity would have to control the $2^{\text {nd }}$ order beliefs of recipients. We focused upon reciprocating behavior that is a decreasing function of those $2^{\text {nd }}$ order expectations. This is our interpretation of what is commonly meant by "gratitude”3 or "thankfulness.” In contrast, the current literature on belief based reciprocity has largely focused on "guilt," which has

\footnotetext{
${ }^{3}$ We are grateful to Luz Marina Arias for pointing out that some people are more likely to reciprocate if they knew that a gift giver had not been expecting anything in return.
} 
been modeled as an increasing function of the beliefs of the receiver/trustee in gift exchange/ trust games.

In this somewhat extended introduction and literature review, we discuss the problems and anomalies in this literature first in order to motivate both our hypothesis of gratitude and our somewhat radical methodology for measuring it. We argue that these largely center around the difficulties of controlling $2^{\text {nd }}$ order beliefs when players are fully aware of the game structure. We also show that though prior work tested for an alternative hypothesis, we are able to find support for our hypothesis in their data. We then discuss the implications of our study for why positive reciprocity has been difficult to find.

The guilt based reciprocity literature hypothesizes that people reciprocate out of disappointment aversion. Charness and Dufwenberg (2006; hereafter, CD) showed that the making of cheap talk promises prior to trust games were correlated with the average giving of trustors, and the average reciprocation by trustees. Furthermore, average trustees' $2^{\text {nd }}$ order belief in reciprocation is correlated with average reciprocation by trustees. However, CD did not reveal the actual beliefs of trustors to the trustees with whom they were paired. Thus, they could not establish causation. Ellingsen et al. (2010) in an attempt to establish causation, revealed the actual belief of each trustor to a paired trustee. They found that the trustor's belief had no significant effect on the paired trustee’s reciprocation, seemly refuting the guilt based reciprocity hypothesis. Particularly interesting for our gratitude hypothesis was the fact that the majority of trustees who faced the most pessimistic beliefs of trustors reciprocated the most. This suggests a counter-guilt factor consistent with our gratitude based reciprocation hypothesis. 
Reuben et al. (2009) tested the guilt based reciprocation hypothesis with a different design. To get trustors to truthfully reveal their expectations to trustees, Ellingsen et al. (2010) did not tell trustors that their beliefs would be revealed to trustees. To get trustees to believe that trustors had been truthful, they told the fact of the omission to trustees. Reuben et al. (2009) did not use asymmetric instructions, which might cause trustees to question whether the experimenter had been forthright with them as well. Subjects played twice in each role of sender and receiver. Reuben et al. (2009) elicited subjects' beliefs when they were senders during a round when beliefs were unused, and then used them in the $2^{\text {nd }}$ round. Reuben et al. (2009) also used significantly higher payments for both belief elicitation and for actual play. They did find a significant correlation between revealed beliefs of trustors and the reciprocating behavior of the paired trustees. However, even here when beliefs were well controlled, about $10 \%$ of subjects went in the opposite direction predicted by guilt in each of their pessimistic and optimistic belief treatments.

Stanca et al.’s (2007) study of intrinsic motivation suppressed $2^{\text {nd }}$ order beliefs in a non-equilibrium setting. In their setup, the $1^{\text {st }}$ player was not informed of the possibility of reciprocation in the $2^{\text {nd }}$ stage. Hence, their $2^{\text {nd }}$ player could not discount the kindness intent of $1^{\text {st }}$ player giving as being merely done in anticipation of reciprocation. They found significantly increased positive reciprocation as compared to their full information control for their strategy elicitation (though not for their decision method elicitation). However, with respect our hypothesis, this design does not indentify gratitude since guilt is still a possible confound. They controlled for guilt from ex-ante but not ex-post expectations. The $1^{\text {st }}$ dictator was informed of the game structure in the $2^{\text {nd }}$ stage. Guilt of the $2^{\text {nd }}$ player was still possible from the disappointment of ex-post expectations. Hence, aversion to possible disappointment could still drive reciprocation. Furthermore, 
unrelated to their hypothesis, but relevant to our gratitude hypothesis, people could reciprocate from shame. There was no "silent exiting” (Dana et al., 2006). Subjects could not give 0 or low and not be noticed. The design was also not double-blind. Subjects might be motivated by shame from experimenter or other subjects knowing about nonreciprocation (Hoffman et al., 1994, 1996).

We adopted a design similar to Stanca et al., but had more controls for the above mentioned confounds, and found strong evidence for positive reciprocity. In contrast to Stanca et al., the proportion of subjects who reciprocated, as well as the proportion of endowment given back by our recipients who received a positive transfer, was significantly higher than both our dictator and standard trust games control.

Furthermore, our results for this apparent positive reciprocity were less likely to have been motivated by guilt as might have been the case in Stanca et al. or inequity aversion, efficiency, or shame, as might have been the case in (McCabe et al., 2003). As in Stanca et al., we controlled for guilt from anticipation of disappointing ex-post expectation by also not informing the $1^{\text {st }}$ round dictator of the possibility of a $2^{\text {nd }}$ round. However, we also further diminished the possibility of guilt from ex-post beliefs by permitting implicit silent exiting with our payment procedure. Inequity aversion as the motive for reciprocation was ruled out in the results.

The fact that trustees gave significantly more when they were less sure that they were expected to reciprocate suggests that guilt crowds out gratitude. This could help explain the conflicting results in Ellingsen et al. 2010 and Reuben et al. 2009, as well as the scarcity of results on positive reciprocity in prior experiments mentioned by Charness and Rabin (2002). First, the opposition between these belief based incentives of guilt and 
gratitude could make guilt experiments very sensitive to the beliefs of subjects. Similar experiments are likely to yield conflicting results for even slightly different setups. Secondly, if guilt can crowd out gratitude, trustees could discount the generosity of trustors giving as motivated by anticipation of reciprocation. This could help explain the paucity of evidence for positive reciprocity.

\section{EXPERIMENTAL DESIGN}

We highlight the novel part of the design first before going into details. We used the decision method of elicitation. To avoid strategic behavior, we gave our subjects instructions step-by-step. We broke the trust game into a two stage dictator game. The $1^{\text {st }}$ stage dictator ( $1^{\text {st }}$ dictator) was not informed of the $2^{\text {nd }}$ stage to prevent the $1^{\text {st }}$ dictator from giving to incite guilt, and also to prevent the $2^{\text {nd }}$ dictator believing that it was the $1^{\text {st }}$ dictator's motive in giving. The $2^{\text {nd }}$ stage dictator $\left(2^{\text {nd }}\right.$ dictator) was informed of the game structure and the $1^{\text {st }}$ dictator's lack of knowledge of the $2^{\text {nd }}$ round, and thus also of the possibility of reciprocation by the $2^{\text {nd }}$ dictator. To avoid guilt from ex-post expectations, the $2^{\text {nd }}$ dictator was told that the 1 st dictator would not be informed about the source of the money, which we sent by electronic bank transfer with the money which they did not give to the $2^{\text {nd }}$ dictator.

The following is a summary of the procedures. Please refer to the game tree in Figure 1.

In Stage 1, subjects were told that they could divide $20 \mathrm{CNY}$ with another player and that the remainder would be sent to their bank account in 3-4 days. Hence, dictator 1's payoff was 20-x, where $\mathrm{x}$ was the amount sent to dictator 2 . As mentioned, the 
dictator $1 s^{\prime}$ were not informed of possibility that the $2^{\text {nd }}$ dictators could reciprocate. The payment was through a non-descript electronic deposit which the $1^{\text {st }}$ dictators might not even notice as including an extra payment.

In Stage 2 , the $2^{\text {nd }}$ dictators received $3^{*}$ transfer from the $1^{\text {st }}$ dictator + show-up fee of $5 \mathrm{CNY}$. Then the $2^{\text {nd }}$ dictators could decide to give something back. Hence, dictator $2 \mathrm{~s}$ got $3 \mathrm{x}+5-\mathrm{y}$, where $\mathrm{y}$ was the amount sent to dictator 1 s. Dictator 1's final payment was $20-\mathrm{x}+\mathrm{y}$

Dictator $2 \mathrm{~s}$ were informed that the $1^{\text {st }}$ stage dictators were not informed about possibility of reciprocation. Reciprocated money was sent with the stage 1 payment to dictator 1 . The $2^{\text {nd }}$ dictators took what money they did not give back upon leaving the experiment.

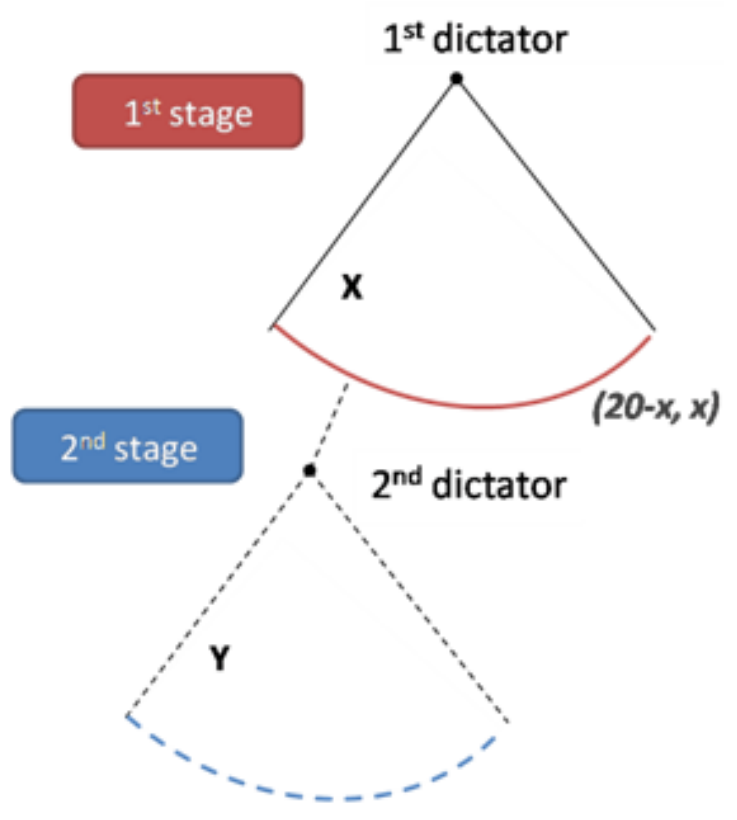

$(20-x+y, 3 x+5-y)$

FIGURE 1: GAME TREE OF THE EXPERIMENT 
The experiment involved 90 subjects recruited from graduate students at Shenzhen University Town. For the main treatment, 70 subjects were put into 35 pairs in the two stage dictator game. "Control 1" is the decision of the $1^{\text {st }}$ dictators (while the main treatment was the decision of the $2^{\text {nd }}$ dictator). The other 20 subjects were in the standard trust game. "Control 2" is the decision of these trustees. Figure 2 shows the main forms that subjects filled out. We elicited the factual $2^{\text {nd }}$ order beliefs of the trustees in control 2 as to the expectations of the trustor. We also elicited the counterfactual $2^{\text {nd }}$ order beliefs of the $2^{\text {nd }}$ dictators about the first dictators expectations for reciprocation had they known about the $2^{\text {nd }}$ stage in the treatment. See appendix A for the translation of the instructions.

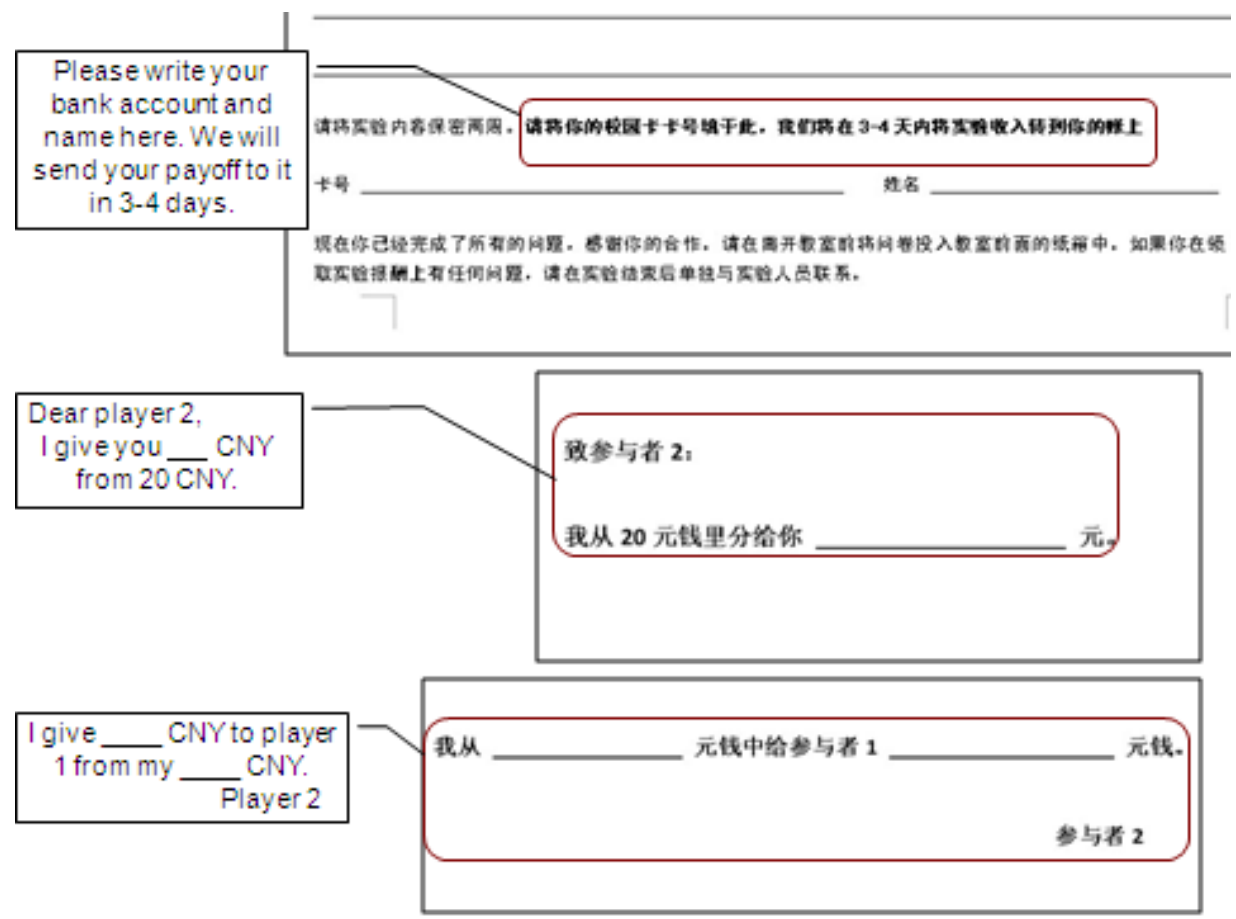

FIGURE 2. FORMS USED IN THE EXPERIMENT 


\section{MAIN RESULTS}

The summary of our main results is as follows. In our control $1,22 / 35=63 \%$ of our 1st dictators gave a positive amount. This is the standard result. The mean giving (ratio of the average) of these subjects was $4.4 / 20 \mathrm{CNY}=22 \%$ (same as the average of the ratio). In control 2, $8 / 10=80 \%$ of these trustees in this standard trust game reciprocated. Mean giving was 6.3/21.5 $\mathrm{CNY}=29 \%$, with the average of the ratio being $31 \%$. However, in the treatment, $22 / 22=100 \%$ of the 2 nd dictators who received positive transfers from the 1 st dictator reciprocated ${ }^{4}$. Mean giving: $10.8 / 26 \mathrm{CNY}=41 \%$, with the average of the ratio being 39\%. The difference in mean giving to the trust game control was significant at the $5 \%$ level, while that to the 1 st stage dictator game was significant at the $1 \%$. Inequity aversion was also ruled out by the result. $2 / 35=5.7 \%$ of the 1 st dictator gave more than half of their endowment. (Only these $1^{\text {st }}$ dictators could have thought they were poorer than their $2^{\text {nd }}$ dictator pair, given that they did not know their transfer would be multiplied by 3 and have 5 CNY added.) However, 17/22=77\% of the $2^{\text {nd }}$ dictators who received a positive amount from 1st dictators were poorer than their 1st dictator pair, after giving. These $2^{\text {nd }}$ dictators knew the true payoffs of the 1 st dictators. This rules out inequity aversion as their motive for giving. The ratios of transfers and the average ratios of each

\footnotetext{
${ }^{4}$ There was one $1^{\text {st }}$ dictator who transferred $0.1 \mathrm{CNY}$. Since 0.1 is much closer to 0 than any other positive transfers, we did not include the $2^{\text {nd }}$ dictator who received this 0.1 into the data of $2^{\text {nd }}$ dictators who received amounts greater than 0 .
} 
treatment group are shown in Figure 3.

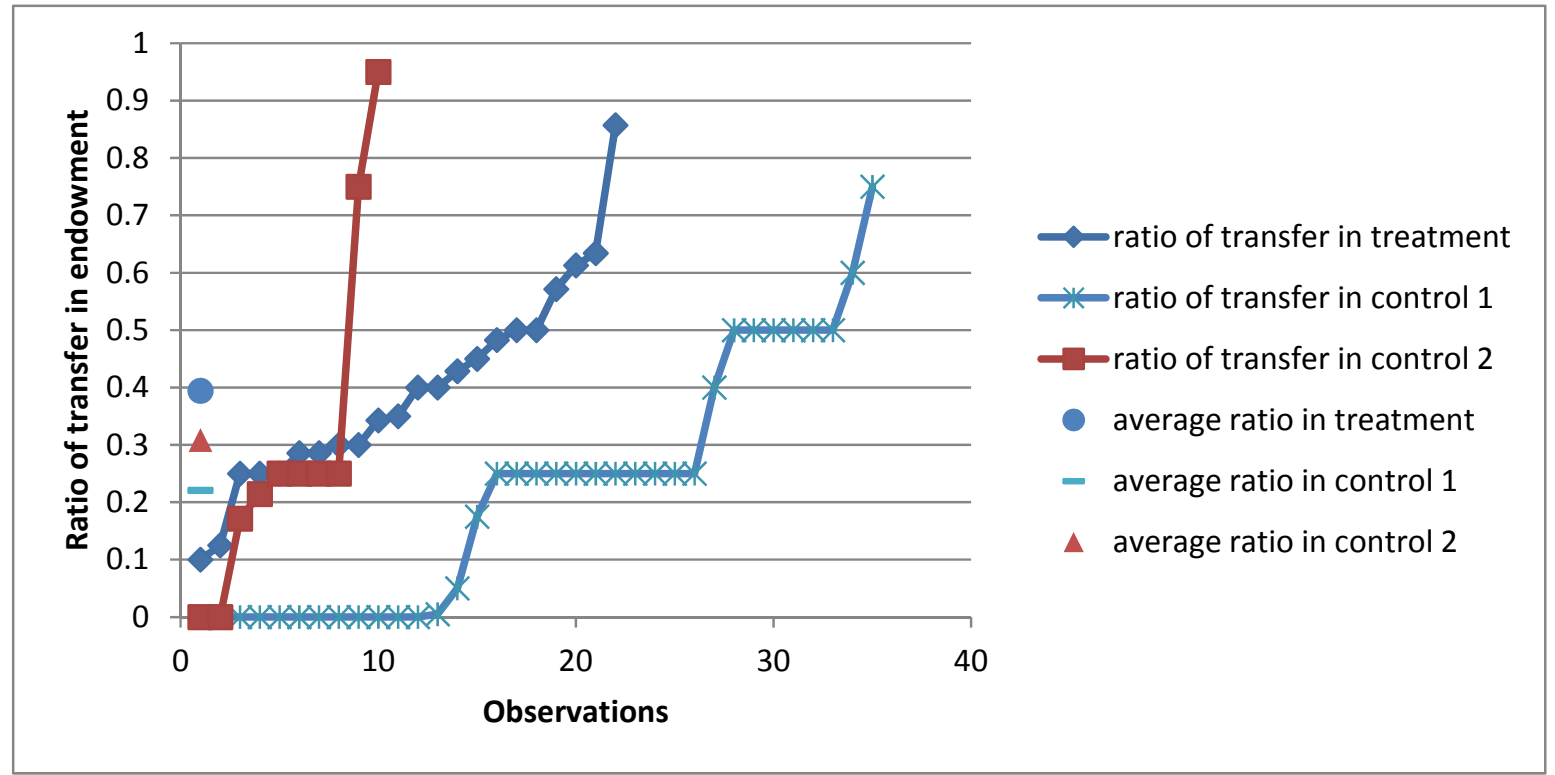

FIGURE 3. RATE OF TRANSFER

We also tested for the guilt sensitivity of all subjects using a standard test from psychology, the TOSCA-3. See Tangney et al., 2002 for details. We gave them the test in part as a distracter since they might have found it strange to get "money for nothing". We found no significant correlation between guilt sensitivity either in 1st dictator giving, or in $2^{\text {nd }}$ dictators reciprocation, or trustees reciprocation in the standard trust game. The lack of significance of the $2^{\text {nd }}$ dictator reciprocation would be predicted if gratitude is something distinct from guilt. The lack of significance with $1^{\text {st }}$ dictator giving could be due to irrelevance of guilt as a motive. The lack of significance with trustee giving in the standard trust game could be due to small sample size, which in this case was 10 subjects.

\section{DISCUSSION}

Our results are significantly stronger than Stanca et al. (2007)’s results. There, identical with us, $1^{\text {st }}$ dictator's transferred $22 \%$ of their endowment in treatment. 
However, their $2^{\text {nd }}$ dictator reciprocation decreased to $12 \%$ for strategy method elicitation and $10 \%$ for decision method elicitation. That is considerably less than our $41 \%$ decision method elicitation. We chose the decision method because prior studies had shown that the strategy method may not be a reliable tool to measure reciprocity. Fehr et al. (2003) concluded that the strategy method is less emotionally arousing than the game method. Casari and Cason (2009) concluded that measured trustworthiness is lower using strategy method elicitation. Our results could also be stronger because people in China are less accustomed to giving by strangers. Hence, the surprise might cause them to reciprocate more.

Lazear et al. (2011) also had a two stage dictator game with an uninformed $1^{\text {st }}$ dictator and a $2^{\text {nd }}$ dictator who could silently exit. They found significant silent exiting by the $2^{\text {nd }}$ dictator (31\%), where we found none. However, they restricted the choice set of $1^{\text {st }}$ dictators to either $(7,5)$ or $(6,6)$, which meant that $1^{\text {st }}$ dictators could only give $14 \%$ of their endowment. This would have made an important difference in our experiment where only one of our $221^{\text {st }}$ dictators transferred less than $14 \%$. Limiting the amount of giving by $1^{\text {st }}$ dictators could induce a norm/reference point for the $2^{\text {nd }}$ dictator to follow. More importantly, such a ceiling on giving would limit the gratitude that the $2^{\text {nd }}$ dictators could feel. Furthermore, if “type preference” as introduced by Gul and Pesendorfer 2010 was a motive for the $2^{\text {nd }}$ dictators' giving, then $1^{\text {st }}$ dictators' signal of the generosity of their type would be hampered. Under such a restricted choice, a specific $2^{\text {nd }}$ dictator could only know that their paired 1st dictator was not mean. That might warrant only a similar lack of meanness from the $2^{\text {nd }}$ dictator - silent exiting. Furthermore, the lowered ex post belief of the $1^{\text {st }}$ dictator, which could have been anticipated by the $2^{\text {nd }}$ dictator should the $2^{\text {nd }}$ dictator not silently exit, would induce less guilt aversion in the $2^{\text {nd }}$ dictator, decreasing 
the amount of giving when $2^{\text {nd }}$ dictator does actually not silently exit. Small amounts of money may also have counter intuitive incentive effects as suggested by Gneezy and Rustichini (2000).

There are several possible limitations to our study. First, we assumed like Stanca et al. (2007) but did not prove that by not informing $1^{\text {st }}$ dictators about the possibility of the $2^{\text {nd }}$ dictator reciprocating, we had diminished the ex ante $2^{\text {nd }}$ order belief of the $2^{\text {nd }}$ dictator that the first dictator was expecting reciprocation. We did survey for the counterfactual beliefs of the $2^{\text {nd }}$ dictator of about $1^{\text {st }}$ dictator beliefs had the $1^{\text {st }}$ dictator known about the $2^{\text {nd }}$ round. Unlike Ellingsen et al. 2010, this was highly significantly correlated with actual $2^{\text {nd }}$ dictator reciprocation. This is evidence that ex-post beliefs mattered, and therefore, could drive guilt driven reciprocity, as we suggested was a limitation of Stanca et al. (2007) with respect to testing our gratitude hypothesis.

This significant correlation, though would not be additional evidence for guilt based reciprocity. $2^{\text {nd }}$ dictator giving and $2^{\text {nd }}$ order counter-factual beliefs could have been driven by the amount and the implied beliefs of $1^{\text {st }}$ dictator giving. In other words, the $2^{\text {nd }}$ dictator gave more when he had more to give, not only because he believed that $1^{\text {st }}$ dictator expected more. We could not separate the independent effects of endowment and implied beliefs on $2^{\text {nd }}$ dictator giving. $2^{\text {nd }}$ order beliefs and the endowment had a correlation of 0.93 . The consequent multi-collinearity yielded no significant regression. What the correlation does suggest is that the $2^{\text {nd }}$ order beliefs would have been a confound for the apparent generosity of $1^{\text {st }}$ dictator giving had the counter-factual world been true, supporting our and Stanca et al. (2007)'s results that people might reciprocate more when they do not believe that the reciprocation had been expected. The $2^{\text {nd }}$ order 
beliefs of trustees in the control group confirmed results from CD 2006. These were correlated with trustee giving at less than $1 \%$ level of significance when regressed on both $2^{\text {nd }}$ order beliefs and the endowment from the trustor.

Second, our silent exiting for $2^{\text {nd }}$ dictators was implicit. $2^{\text {nd }}$ dictators were told that $1^{\text {st }}$ dictators were uninformed about the existence of the $2^{\text {nd }}$ round. Furthermore, they were told that the $1^{\text {st }}$ dictators would not be told that the money was from them, the $2^{\text {nd }}$ players, should they choose to reciprocate. To see that this implies silent exiting, note that the statement which rules out silent exiting, “ 1 st dictator will be told that you did not give back anything" would be inconsistent with the spirit and the letter of this instruction ${ }^{5}$. In any case, the effect of guilt should be weaker than in either standard trust games or in Stanca et al.'s design, if not eliminated. Third, the double-blindness in our experiment was also implicit and unannounced. We simply had no identifiers for $2^{\text {nd }}$ dictators' identity on the envelopes they submitted for giving. We chose not to make our doubleblindness more salient in order to avoid possible demand effects (George Loewenstein, 1999). Furthermore, Barmettler et al. (2011) found no difference between implicit double-blindness and explicit double-blindness. If the double-blindness was not salient, then subjects might still feel some shame from “appearing” ungrateful before experimenter, in which case, it would be a $2^{\text {nd }}$ order reaction to gratitude. The use of implicit silent exiting and double-blindness should in any case have decreased both shame and guilt and hence should not have led to significantly increased rates of reciprocation in our treatment, if shame and guilt were the cause.

\footnotetext{
5 The exact statement was "They were not told about the existence of this round. That means, when player 1 made their choice (to give to you), Player 1s were not told the amount they transferred will be multiplied by 3 and plus 5 . They were also not told that you can pay them back in this round. They will not be told that the money is given by you."
} 
Third, we also had a small number of observations. However, our results should be read as a partial replication of Stanca's et al. As was suggested in the introduction, our hypothesis was corroborated as the driver of the contra-guilt data in Ellingsen et al. (2010) and in Reuben et al. (2009), and in the apparent conflict between their main results.

Fourth, we leave for future work how to reconcile gratitude and guilt within a general model of reciprocity. As mentioned in the introduction, our strong result when guilt was suppressed suggests that gratitude is not merely a substitute for guilt, but can be “crowded out” by guilt. How this crowding out occurs and what determines whether a person feels gratitude or guilt is beyond the scope of this paper. However, one possible reason for our results is that part of gratitude is motivated by "type preference." $2^{\text {nd }}$ dictators might like to give more to those $1^{\text {st }}$ dictators who gave them more because $2^{\text {nd }}$ dictators prefer to give more to people who have shown themselves to be more altruistic. To test this, Lin and Ong 2011 introduced a $3^{\text {rd }}$ dictator (30 subjects) who observed $1^{\text {st }}$ dictator giving to $2^{\text {nd }}$ dictator, and could give to $1^{\text {st }}$ dictator from 3 exogenous levels of endowment: 6, 20, 32 CNY. They also had implicit and explicit double-blindness and silent exiting treatments. They found that $3^{\text {rd }}$ player giving correlated with $1^{\text {st }}$ dictator giving but not with endowment when regressed on both in all cases except for the $6 \mathrm{CNY}$ explicit double-blindness and silent exiting treatment. In that case the correlation was inverted. They suggest that this could be a demand effect interacting with the small endowment. They also found no difference between explicit and implicit doubleblindness except for the $6 \mathrm{CNY}$. Their result supports our result, and suggests that type preferences contributed to reciprocation in our experiment. Thus, their result seems to address the limitations we mentioned above in regards to separating the belief from 
endowment effect, and the saliency of implicit double-blindness and silent exiting, and sample size.

In summary, our results suggest that guilt and inequity aversion are unnecessary for reciprocation. Gratitude can also drive reciprocation. We found greater reciprocation when guilt was ruled out, suggesting that guilt might crowd out gratitude. Our result could help explain opposing results in Ellingsen et al. (2010), Reuben et al. (2009). The opposing belief dependent incentives would make experiment sensitive to setup. Our strong positive reciprocity result also suggests why it has been difficult to find in the past.

\section{REFERENCES}

Barmettler, F.; Fehr, E. \& Zehnder, C. (2011), 'Big Experimenter Is Watching You! Anonymity and Prosocial Behavior in the Laboratory'(5925), Technical report, Institute for the Study of Labor (IZA).

Casari, M. \& Cason, T. N. (2009), 'The strategy method lowers measured trustworthy behavior', Economics Letters 103(3), 157 - 159.

Charness, G. \& Dufwenberg, M. (2006), 'Promises and Partnership', Econometrica 74(6), 1579--1601.

Charness, G. \& Rabin, M. (2002), 'Understanding Social Preferences With Simple Tests', The Quarterly Journal of Economics 117(3), 817-869.

Dana, J.; Cain, D. M. \& Dawes, R. M. (2006), 'What you don't know won't hurt me: Costly (but quiet) exit in dictator games', Organizational Behavior and Human Decision Processes 100(2), 193 - 201.

Elizabeth, H.; Kevin, M.; Keith, S. \& Vernon, S. (1994), 'Preferences, Property Rights, and Anonymity in Bargaining Games', Games and Economic Behavior 7(3), 346-380.

Ellingsen, T.; Johannesson, M.; Tjøtta, S. \& Torsvik, G. (2010), 'Testing guilt aversion', Games and Economic Behavior 68(1), 95 - 107.

Fehr, E.; Fischbacher, U.; von Rosenbladt, B.; Schupp, J. \& Wagner, G. G. (), 'A NationWide Laboratory: Examining trust and trustworthiness by integrating behavioral experiments into representative surveys'(iewwp141), Technical report, Institute for 
Empirical Research in Economics - University of Zurich.

Gul, F. \& Pesendorfer, W. (2010), 'Interdependent Preference Models as a Theory of Intentions', Technical report, Working paper.

Hoffman, E.; McCabe, K. \& Smith, V. L. (1996), 'Social Distance and Other-Regarding Behavior in Dictator Games', American Economic Review 86(3), 653-60.

Lazear, E.; Malmendier, U. \& Weber, R. (2011), Sorting in experiments with application to social preferences, American Economic Journal: Applied Economics, forthcoming..

Loewenstein, G. (1999), 'Experimental Economics from the Vantage-Point of Behavioural Economics', Economic Journal 109(453), F23-34.

Lin, H. \& Ong, D. (2011), 'Deserving Altruism: Type Preferences in the Laboratory', unpublished.

McCabe, K. A.; Rigdon, M. L. \& Smith, V. L. (2003), 'Positive reciprocity and intentions in trust games', Journal of Economic Behavior \& Organization 52(2), 267-275.

Reuben, E.; Sapienza, P. \& Zingales, L. (2009), 'Is mistrust self-fulfilling?', Economics Letters 104(2), 89-91.

Stanca, L.; Bruni, L. \& Corazzini, L. (2009), 'Testing theories of reciprocity: Do motivations matter?', Journal of Economic Behavior \& Organization 71(2), 233-245.

Tangney, J. P. \& Dearing, R. L. (2003), Shame and Guilt (Emotions And Social Behavior), The Guilford Press. 